AperTO - Archivio Istituzionale Open Access dell'Università di Torino

\title{
Transparent microelectrode array in diamond technology
}

\section{This is the author's manuscript}

Original Citation:

Availability:

This version is available http://hdl.handle.net/2318/79892

since

Published version:

DOI:10.1007/s12213-010-0032-3

Terms of use:

Open Access

Anyone can freely access the full text of works made available as "Open Access". Works made available under a Creative Commons license can be used according to the terms and conditions of said license. Use of all other works requires consent of the right holder (author or publisher) if not exempted from copyright protection by the applicable law. 


\section{Transparent microelectrode array in diamond technology}

Journal of Micro-Nano

Mechatronics

ISSN 1865-3928

Volume 6

Combined 1-2

J. Micro-Nano Mech. (2010)

6:33-37

DOI $10.1007 /$

s12213-010-0032-3

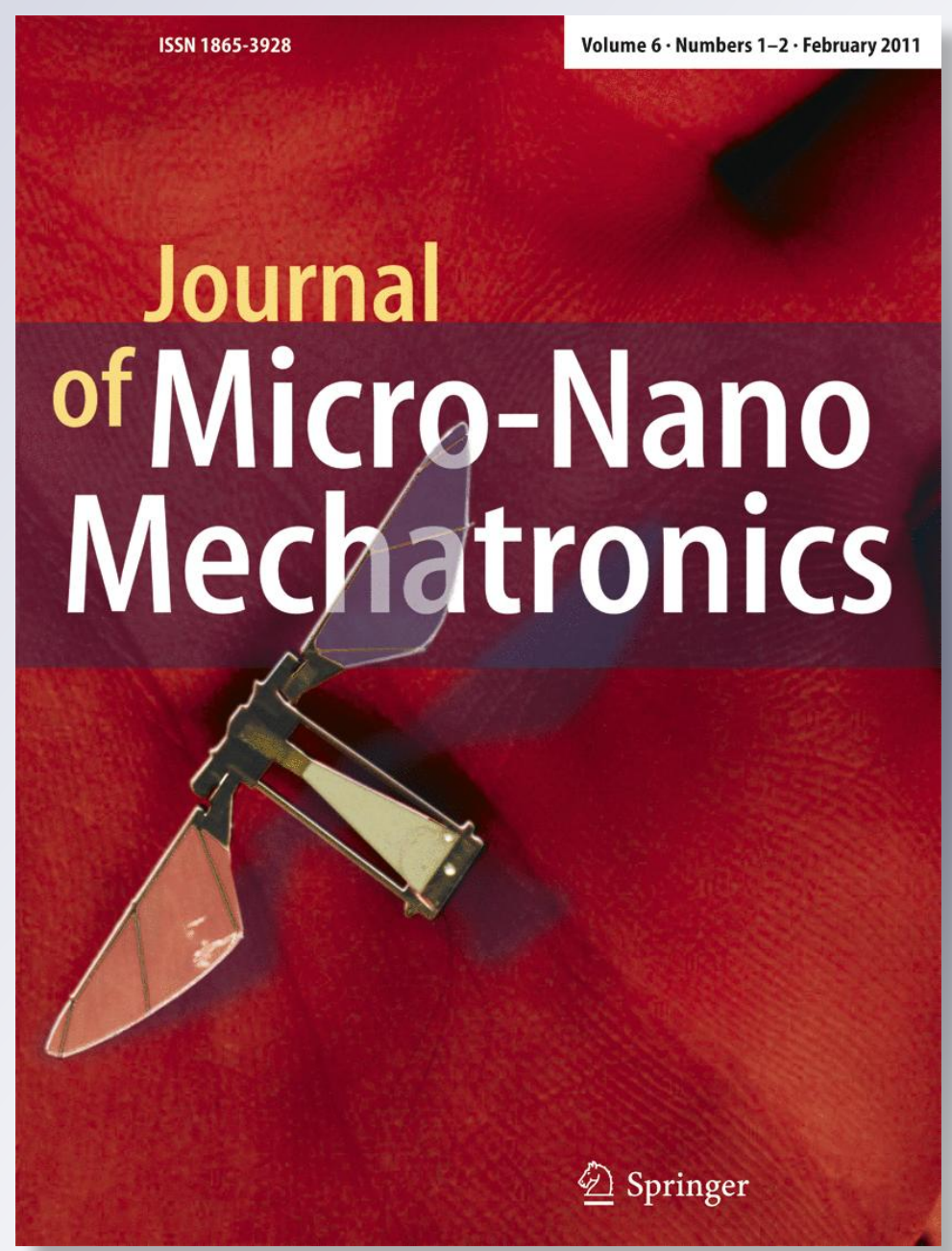

然 Springer 
Your article is protected by copyright and all rights are held exclusively by SpringerVerlag. This e-offprint is for personal use only and shall not be self-archived in electronic repositories. If you wish to self-archive your work, please use the accepted author's version for posting to your own website or your institution's repository. You may further deposit the accepted author's version on a funder's repository at a funder's request, provided it is not made publicly available until 12 months after publication. 


\title{
Transparent microelectrode array in diamond technology
}

\author{
Ziyao Gao • Valentina Carabelli • Emilio Carbone • Elisabetta Colombo • \\ Michele Dipalo • Chiara Manfredotti • Alberto Pasquarelli • Martin Feneberg • \\ Klaus Thonke $\cdot$ Ettore Vittone $\cdot$ Erhard Kohn
}

Received: 30 March 2010 /Accepted: 8 December 2010 /Published online: 21 December 2010

(C) Springer-Verlag 2010

\begin{abstract}
We report on the development of a diamond-onsapphire microelectrode quadrupole array, substituting the commonly used inert metal electrode material by nanocrystalline diamond (NCD). This allows to combine the transparency (desired for fluorescence analysis) with the properties of an inert quasi-metallically doped diamond electrode. The NCD film was nucleated by BEN (Bias Enhanced Nucleation) on double side polished sapphire substrates and outgrown by hot filament CVD. Early quadrupole results on isolated adrenal chromaffin cells show the detection of amperometric signals corresponding to the quantal release of catecholamines contained in a single nanometric secretory vesicle.
\end{abstract}

Keywords MEA · Nanodiamond Cell secretion analysis

Z. Gao $(\bowtie) \cdot$ M. Dipalo $\cdot$ A. Pasquarelli $\cdot$ E. Kohn

Institute of Electron Devices and Circuits, Ulm University,

Albert-Einstein-Allee 45,

Ulm 89081, Germany

e-mail: zi-yao.gao@uni-ulm.de

V. Carabelli $\cdot$ E. Carbone $\cdot$ E. Colombo

Department of Neurosciences and NIS Center, CNISM Unit,

University of Torino,

Torino, Italy

C. Manfredotti $\cdot$ E. Vittone

Experimental Physics Department and NIS Center,

University of Torino,

Torino, Italy

M. Feneberg $\cdot \mathrm{K}$. Thonke

Institute of Semiconductor Physics, Ulm University,

Albert-Einstein-Allee 45,

Ulm 89081, Germany

\section{Introduction}

Planar microelectrode arrays are commonly used to detect amperometric and voltammetric signals in electroanalysis and biomedical sensing like in the in-vivo characterization of cell membrane channel activities. They are mostly based on a patterned array of inert metal electrodes (like Au or Pt) deposited onto $\mathrm{Si}$, glass or plastic substrates. Metal electrodes allow the analysis of redox activities within the water dissociation window $(\sim 1.5 \mathrm{~V})$, not easily allowing the detection of organic molecules with higher oxidation potential (like phenols). In the case of Boron Doped Diamond (BDD), water dissociation is suppressed across a wider potential window $(\sim 3 \mathrm{~V})$, where the detection of substances like dopamine, histamine and even phenols has already been reported [1]. In addition, metal electrodes are non-transparent and do not allow high resolution fluorescence imaging from the backside of the sample. Even the surrounding silicon on which they are located is only transparent in the IR range, while bio-glass may display a cut-off wavelength in the mid-UV, depending on its composition [2]. Diamond on the contrary, possessing a semiconductor bandgap of $5.47 \mathrm{eV}$, is transparent between $225 \mathrm{~nm}$ and $12 \mu \mathrm{m}$ [3]. NCD has been deposited onto transparent substrates like sapphire, glass and even high temperature stable plastic [4-6]. However, up to now the properties of the deposited nanocrystalline films have not been discussed in conjunction with biochemical and electrochemical applications, which require high corrosion resistance. In addition, the diamond surface can be functionalized in many ways to tailor its electrochemical sensitivity or further improve its already high biocompatibility $[1,7]$. An oxygen termination is mostly used, like in this investigation, resulting in a highly corrosion resistive surface. 
We report here on the realization of a first simple quadrupole array with quasi-metallically doped diamond electrodes deposited onto a double side polished sapphire substrates. First amperometric tests have been performed on mouse adrenal chromaffin cells. The measurements show that diamond MEAs are able to detect quantal releases of catecholamines in terms of amperometric current spikes related to the oxidation of the secreted molecules.

\section{Experimental}

\subsection{Diamond growth and materials characterization}

The NCD electrode material stack has been deposited by hot filament CVD (HFCVD). It contained a nucleation layer on the double polished sapphire substrate, an undoped NCD layer and a highly boron doped top electrode layer. The nucleation layer was Si-based and nuclei generated by a bias enhanced nucleation (BEN) process at $800^{\circ} \mathrm{C}$. This layer may be mostly consumed in the gas phase $(0.75 \%$ $\mathrm{CH}_{4} / \mathrm{H}_{2}$ ) reactions leading to the generation of diamond nuclei and other carbon or Si containing clusters [8]. In spite of its inhomogeneity, this layer has a final thickness in the order of $10 \mathrm{~nm}$, therefore affecting the transparency of the entire stack only to a small extent. The nucleation density has been $\sim 3 \times 10^{10} \mathrm{~cm}^{-2}$. The further outgrowths were performed at $750^{\circ} \mathrm{C}$ in a mixture of $0.3 \% \mathrm{CH}_{4}$ in $\mathrm{H}_{2}$ for both the undoped NCD layer (200 nm) and the highly boron doped top electrode layer $(350 \mathrm{~nm})$, resulting in a total thickness of $\sim 550 \mathrm{~nm}$.

To combine high electrochemical activity with high corrosion resistance, the outgrown NCD film has to contain a low grain boundary density as mentioned before, which is difficult to obtain with ultra-NCD. Furthermore, the grain boundary network should possess high energetic strength (leading to high chemical inertness) and contain therefore a large fraction of low angle grain boundaries. Such a condition has been obtained by $\alpha$-parameter engineering [9] and an outgrowth to an average grain size of $70 \mathrm{~nm}$ (see Fig. 1), usually evaluated by SEM and AFM. The electrochemical "quality" has been assessed by comparison of the cyclic voltammograms with those of a Pt electrode. The optical properties in the wavelength range of $300 \mathrm{~nm}$ to $900 \mathrm{~nm}$ have been determined with a Varian CARY 300 $\mathrm{UV}$-Vis spectrometer.

\subsection{Micro array fabrication}

A micrograph of the micro array is show in Fig. 2. It shows the diamond/sapphire structure passivated with SU-8. The circular area is the active quadrupole opening of around $16 \mu \mathrm{m}$ in diameter exposed to the liquid and cell. The areas

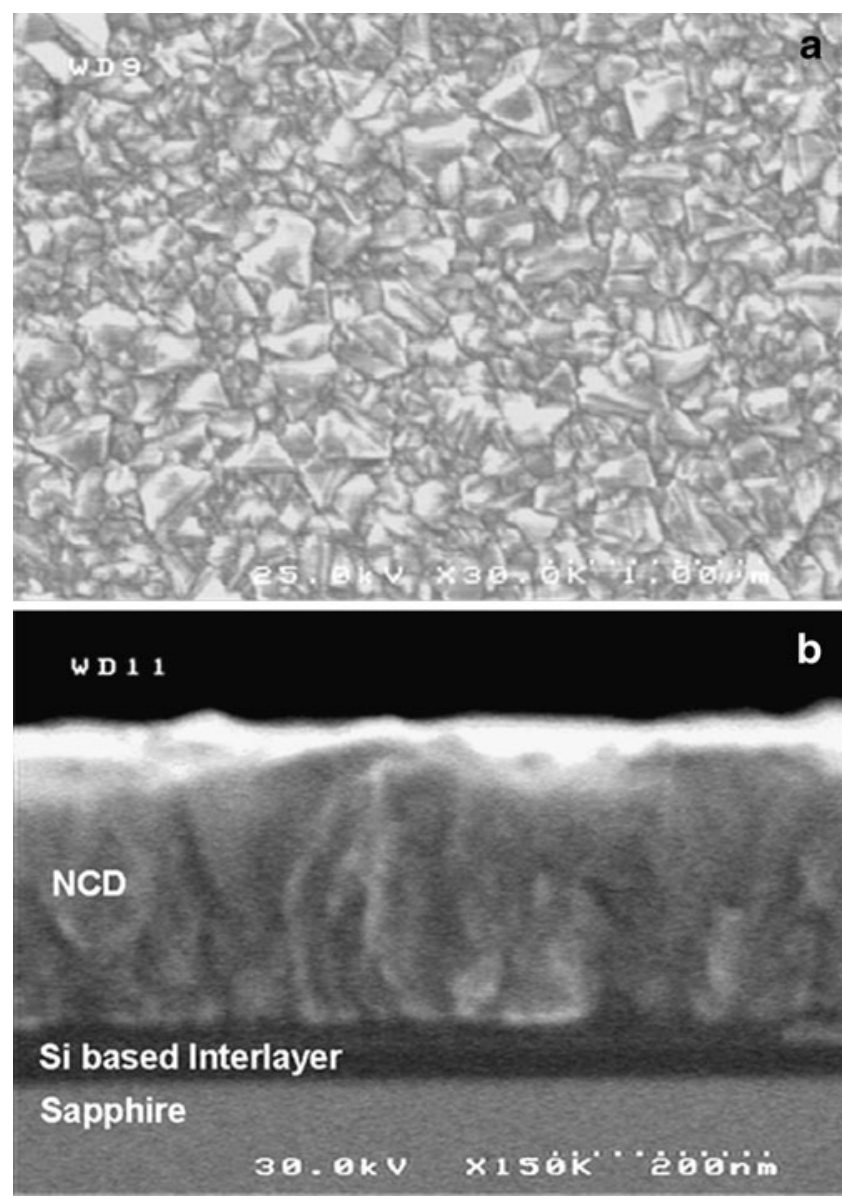

Fig. 1 (a) shows a SEM micrograph of a BDD sample surface, (b) an SEM cross section also showing the Si-based nucleation layer

$\mathrm{A}, \mathrm{B}, \mathrm{C}$ and $\mathrm{D}$ are the four electrodes, reaching into the centre as small triangular structures. The electrodes are separated by $5 \mu \mathrm{m}$ gaps dry etched (by $\mathrm{Ar} / \mathrm{O}_{2}$ ) down to the insulating substrate. Ohmic contacts were obtained by $\mathrm{Ti} / \mathrm{Au}$ metallization at the outside (not shown).

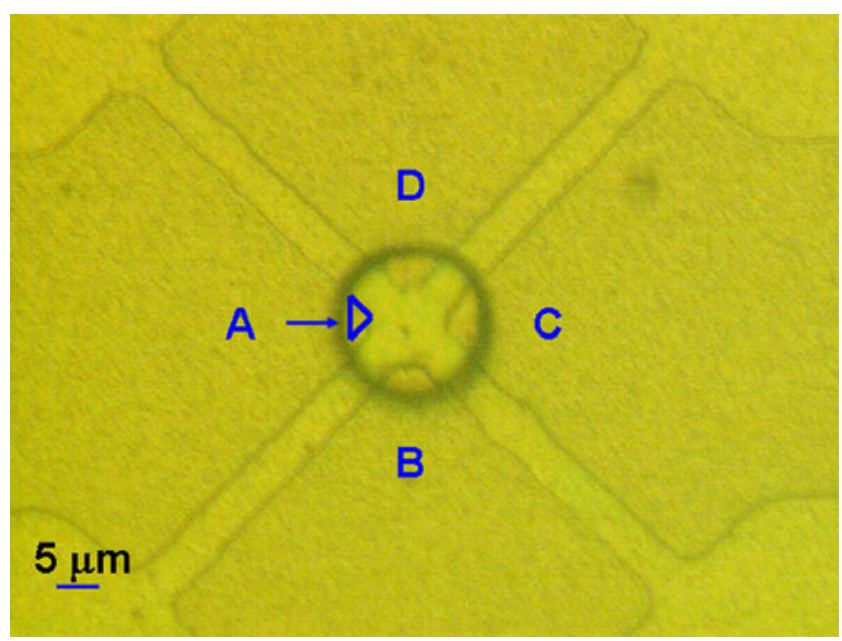

Fig. 2 MEA micrograph as described in the text 


\subsection{Cell preparation and handling}

We isolated chromaffin cells obtained from mouse adrenal glands following a similar procedure used to isolate rat adrenal chromaffin cells [10]. Immediately after excision, the glands were placed in $\mathrm{Ca}^{2+}$ and $\mathrm{Mg}^{2+}$ free Locke's buffer containing (in $\mathrm{mM}$ ): $154 \mathrm{NaCl}, 3.6 \mathrm{KCl}, 5.6$ $\mathrm{NaHCO}_{3}, 5.6$ glucose, and 10 HEPES, pH 7.2, at room temperature. Soon after, the glands were decapsulated and the medulla was precisely separated from the cortex. To obtain the chromaffin cells, the medulla was digested in the Locke's buffer, containing $20 \mathrm{U} / \mathrm{ml}$ of papain (Worthington Biochemical Corp., Lakewood, NJ) for $60 \mathrm{~min}$ at $37^{\circ} \mathrm{C}$. The cell suspension was then centrifuged for $5 \mathrm{~min}$ at $900 \mathrm{rpm}$, washed two times and resuspended in $2 \mathrm{ml}$ DMEM supplemented with $15 \%$ foetal calf serum (FCS). The typical experiment to detect amperometric signals consisted in placing an isolated chromaffin cell on top of the MEA and setting the diamond electrode potential between +650 and $+800 \mathrm{mV}$. The cell was then chemically depolarized by applying an external solution containing $135 \mathrm{mM} \mathrm{TEACl}$ and $10 \mathrm{mM}$ $\mathrm{CaCl}_{2}$ delivered through a perfusion glass pipette pointing the cell. This depolarization causes the opening of voltagegated $\mathrm{Ca}^{2+}$ channels, increases $\mathrm{Ca}^{2+}$ influxes through the open channels and vesicle exocytosis, with consequent release of catecholamines.

Cells signals were sampled with the set-up described in [11].

\section{Results and discussion}

\subsection{Electrode characterization}

The average grain size has been evaluated with around $70 \mathrm{~nm}$ as mentioned before and shown in Fig. 1, while the surface roughness was around $12 \mathrm{~nm}(\mathrm{rms})$ according to AFM images.

Before immersing the electrode into the physiological solution, the surface had to be stabilized, in essence by removing all residual $\mathrm{sp}^{2}$-bonded carbon clusters by anodic treatment in $0.1 \mathrm{M} \mathrm{KOH}$ at $+1.8 \mathrm{~V}$ vs. SCE, in the range of the oxygen evolution reaction. Figure 3 shows the cyclic voltammograms measured after 3 priming cycles in $0.1 \mathrm{M}$ $\mathrm{KCl}$ : the diamond electrode shows the typical potential window of $3.5 \mathrm{~V}(-2.0 \mathrm{~V} \div 1.5 \mathrm{~V}$ vs. SCE), while the Ptblack electrode shows only $1.9 \mathrm{~V}$. Also, the background current level of the diamond electrode differs as expected from $\mathrm{Pt}$ one by around 2 orders of magnitude (scan rate $50 \mathrm{mV} / \mathrm{sec}$ ). The doping concentration extracted from a Mott-Schottky plot shows an average doping concentration of around $3 \times 10^{20} \mathrm{~cm}^{-3}$. When comparing these films with

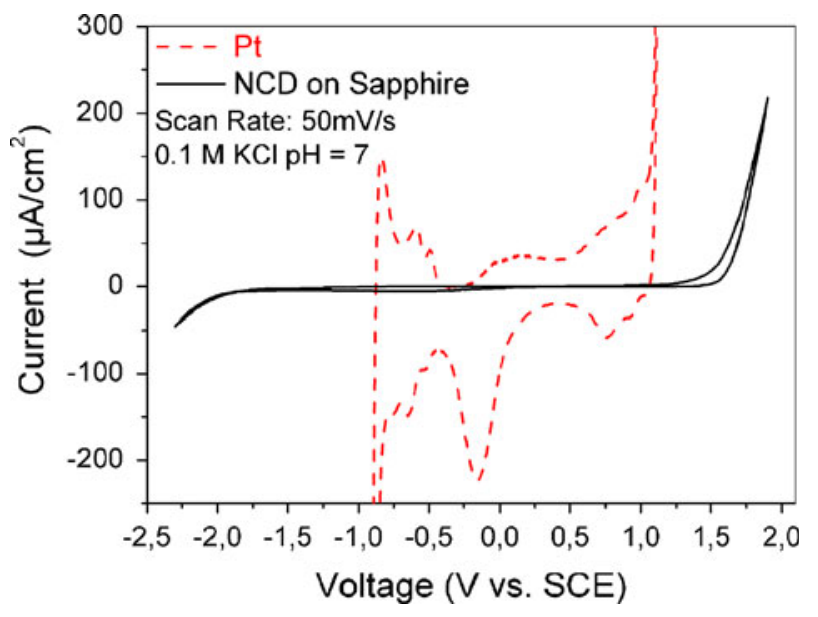

Fig. 3 Cyclic voltammograms of a NCD-on-sapphire electrode compared to a platinum electrode in $\mathrm{KCl}$ solution $(\mathrm{pH}=7)$

NCD grown on silicon under identical outgrowth conditions [12], we can conclude that no degradation of the electrochemical properties, e.g. potential window width and background current level, could be seen.

\subsection{Transparency characterization}

Figure 4 shows the transmittance spectra of two NCD samples: (A) a $200 \mathrm{~nm}$ intrinsic (nominally undoped) layer and a $550 \mathrm{~nm}$ layer stack containing a $200 \mathrm{~nm}$ undoped layer and (B) a $350 \mathrm{~nm}$ boron-doped top electrode layer, the second one being similar to the stack used for the MEA fabrication discussed here. The spectra show different periodicity of the interference patterns due to the two different thicknesses and to the nucleation layer, the latter being more evident for sample (B) in the low wavelength range due to the smaller thickness. A decrease of

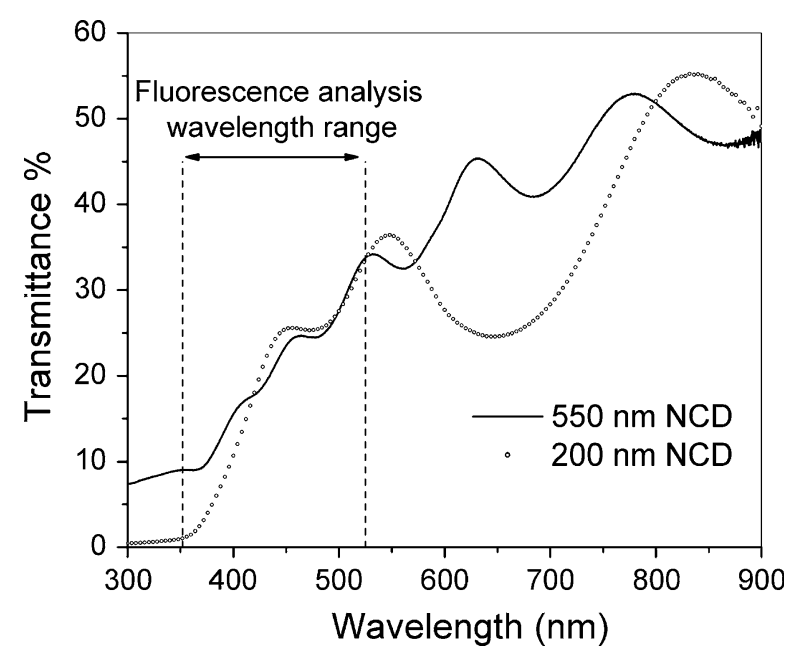

Fig. 4 Transmittance spectra of two NCD samples: a $200 \mathrm{~nm}$ intrinsic layer (a) and a $550 \mathrm{~nm}$ one obtained by overgrowing a $200 \mathrm{~nm}$ undoped layer with a $350 \mathrm{~nm}$ B-doped layer (b) 
transparency with shorter wavelength is observed for both samples. In fact, it is well known that surface roughness, graphitic phases embedded in the bulk, scattering at grain boundaries and thus also the average grain size influence the transmittance of diamond films [4, 13, 14]. In general it is found that ultra-NCD films show higher transparency due to their extremely small grain size [5]. However, the transmittance of diamond films on transparent substrates degrades generally towards lower wavelengths, probably also influenced by properties of the nucleation layer and the nucleation process itself. Usually outgrowth on transparent and electrically insulating films is performed on nanoseeds deposited from a solution. Here BEN is used and little information is available on the optical properties of this nucleation layer.

Both films with a $70 \mathrm{~nm}$ average grain size and a surface suitable for electrochemical applications reveal a maximum transmittance of $\sim 55 \%$ at $800 \mathrm{~nm}$. Furthermore, Fig. 4 depicts the wavelength range usually used for fluorescence analysis, showing a suitable transmittance of the two samples until the blue region of the visible spectrum and confirming the suitability of NCD on sapphire for bio-chips applications.

\subsection{Functional measurement of cell secretion}

Amperometric measurements have been performed on chromaffin cells from mouse adrenal glands. After standard preparation [15], the cells were dispersed in a hyperpolarizing KCl-free solution and placed into the $\sim 0.5 \mathrm{ml}$ perfusion chamber of the MEA. Electronically-controlled micro-manipulators were employed to precisely place one single cell at the time on top of the four electrodes recording area. The NCD electrodes were biased between +650 and $+800 \mathrm{mV}$ as described before, corresponding to the optimal potentials for catecholamines oxidation. Subsequently, a $10 \mathrm{mM} \mathrm{CaCl} / 2 / 135 \mathrm{mM} \mathrm{TEACl}$ solution was applied in order to depolarize the cell and open the voltagegated $\mathrm{Ca}^{2+}$ channels. $\mathrm{Ca}^{2+}$ ions were then able to flow through the open channels causing the $\mathrm{Ca}^{2+}$-dependent release of catecholamines, which chemically oxidize at the diamond surface. Figure 5 shows a group of redox spikes generated and acquired simultaneously a few seconds after the chemical stimulation at the four electrodes A, B, C and $\mathrm{D}$ facing the cell. Persistent activity was detected as long as 2 min after cell depolarization. As shown in Fig. 5, simultaneous signals have distinct peak amplitudes and durations, due to the release of differently sized vesicles containing catecholamines and/or to a diverse vesicle orientation with respect to the diamond electrodes. We revealed spike signals with amplitudes ranging from 5 to $80 \mathrm{pA}$ and durations between few milliseconds and several tens of milliseconds that were comparable in size and shape
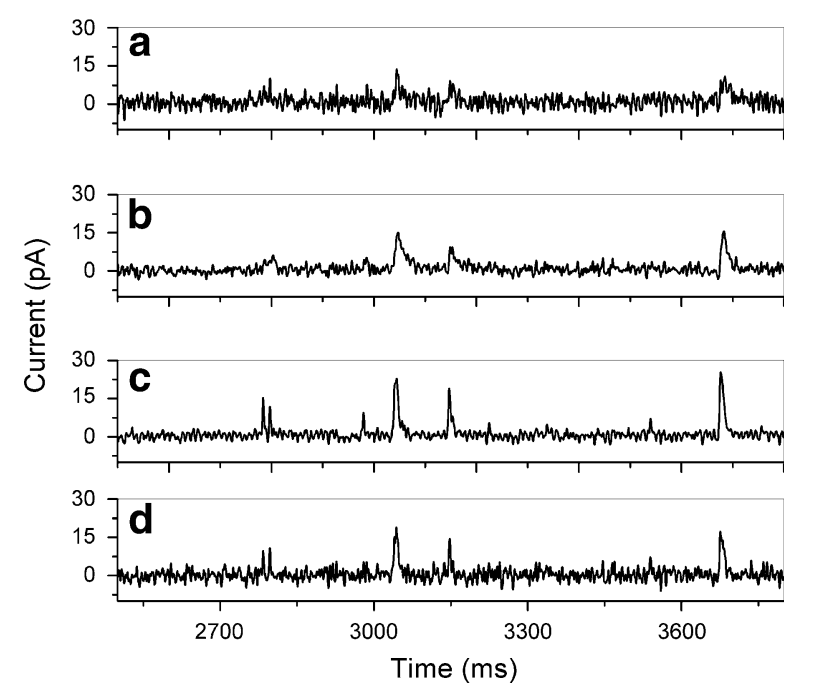

Fig. 5 Simultaneous acquisitions of amperometric "spikes" from the MEA few seconds after a TEACl-induced depolarization of the cell. Each spike corresponds to the oxidation current of the catecholamine molecules contained in a single vesicle which firstly fuses to the cell membrane and then releases its content to the bath. Each recordings last approximately $1.2 \mathrm{~s}$ and shows the sequential fusion and release of five vesicles simultaneously detected from the four NCD microelectrodes

with the amperometric spikes detected using standard carbon microelectrodes with $5 \mu \mathrm{m}$ tip diameter [10].

\section{Conclusion}

A quadrupole microelectrode array based on quasimetallic CVD diamond electrodes (BDD) patterned on a sapphire substrate has been fabricated and tested in the amperometric mode of operation with chromaffin cells from mouse adrenal glands. Amperometric spikes could be clearly detected by the four recording diamond electrodes, corresponding to the oxidation current of the catecholamine molecules. The simultaneous responses of single exocytotic events were detected with a high signal to noise ratio.

The electrodes consisted of a materials stack, containing a nucleation layer, an undoped NCD layer and a highly boron doped electrode layer. Thus, this stack is highly inhomogeneous, generating light scattering and also absorption due to graphitic phases, remaining $\mathrm{Si}$ in the nucleation layer and the high boron doping level of the electrode layer. However, each of these films has been scaled down as much as possible in thickness, still maintaining an average grain size of $70 \mathrm{~nm}$ at the surface. The stack becomes opaque at short wavelength, the reason not being entirely clear at present, since this tendency is also seen for NCD films deposited with different techniques and on various other transparent substrates. Nevertheless in the visible range, fluorescence can be detected and experi- 
ments to combine amperometric measurements and fluorescence labeling seem possible.

These first experiments indicate therefore the possibility to combine cell analysis based and highly localized fluorescence detection with amperometric MEA measurements identifying the dynamic behavior of single cell membrane activities. Thus, diamond based MEAs can indeed combine the features of fluorescence and electrical redox analysis. Moreover, being sapphire a common substrate to GaN-electronics, this materials configuration may eventually enable the combination of high density BDD electrode arrays with GaN electronic on-chip readout [16].

Acknowledgments This work was supported by the "Landesstiftung Baden-Württemberg", the Vigoni program and the Regione Piemonte. The authors want to thank C. Pietzka and Dr.-Ing. F. Demaria for their scientific contribution to this work.

\section{References}

1. Zhou Y, Zhi J (2009) Talanta 79:1189

2. Gardner RD, Zhou A, Zufelt NA (2009) Sens Actuators B 136:177

3. Thomas ME, Tropf WJ, Szpak A (1995) Diamond Films Technol $5: 159$
4. You MS, Hong FCN, Jeng YR, Huang SM (2009) Diamond Relat Mater 18:155

5. Joseph PT, Tai NH, Lee CY, Niu H, Pong WF, Lin IN (2008) Diamond Relat Mater 17:476

6. Daenen M, Williams OA, D'Haen J, Haenen K, Nesládek M (2006) Phys Status Solidi A 203:3005

7. Ariano P, Baldelli P, Carbone E, Gilardino A, Lo Giudice A, Lovisolo D, Manfredotti C, Novara M, Sternchulte H, Vittone E (2005) Diamond Relat Mater 14:669

8. Stöckel R, Stammler M, Janischowsky K, Ley L (1998) J Appl Phys 83:531

9. Wild C, Koidl P, Müller-Sebert W, Walcher H, Kohl R, Herres N, Locher R, Samlenski R, Brenn R (1993) Diamond Relat Mater 2:158

10. Carabelli V, Marcantoni A, Comunanza V, de Luca A, Diaz J, Borges R, Carbone E (2007) J Physiol 584:149

11. Pasquarelli A, Carabelli V, Xu Y, Gao Z, Marcantoni A, Kohn E, Carbone E (2009) Contribution to the 11th World Congress on Medical Physics and Biomedical Engineering, September, Munich (unpublished)

12. Denisenko A, Jamornmarn G, El-Hajj H, Kohn E (2007) Diamond Relat Mater 16:905

13. Franta D, Zajíčková L, Karásková M, Jašek $\mathrm{O}$, Nečas D, Klapetek P, Valtr M (2008) Diamond Relat Mater 17:1278

14. Chen LC, Wang TY, Yang JR, Chen KH, Bhusari DM, Chang YK, Hsieh HH, Pong WF (2000) Diamond Relat Mater 9:877

15. Marcantoni A, Carabelli V, Vandael DH, Comunanza V, Carbone E (2009) Eur J Physiol 457:1093

16. Dipalo M, Gao Z, Scharpf J, Pietzka C, Alomari M, Medjdoub F, Carlin J-F, Grandjean N, Delage S, Kohn E (2009) Diamond Relat Mater 18:88 